\title{
Cholesterol Crystal Deposition in Basal Cell Carcinoma: An Investigation of 4 Cases
}

\author{
Ken Okamura*, Takayuki Konno, Masakazu Kawaguchi, Yuko Abe, Yoriko Yaguchi, \\ Sayaka Ajima, Yutaka Hozumi, Tamio Suzuki \\ Department of Dermatology, Yamagata University Faculty of Medicine, \\ Yamagata, Japan

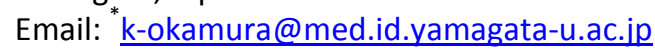

Received 1 July 2015; accepted 21 August 2015; published 24 August 2015

Copyright (C) 2015 by authors and Scientific Research Publishing Inc.

This work is licensed under the Creative Commons Attribution International License (CC BY). http://creativecommons.org/licenses/by/4.0/

(c) (†) Open Access

\begin{abstract}
Cholesterol crystals are a primary cause of cholesterol embolism if they appear in vessels. Various papers have reported the involvement of cholesterol crystal deposition in cutaneous diseases such as xanthoma. However, no cases of cholesterol crystal involvement in cutaneous cancer have been reported. We report four cases of basal cell carcinoma with cholesterol crystal deposition, and discuss the mechanism(s) of the condition. Disease duration, anatomical site, histopathological features, and serum lipid profiles were investigated. The median disease duration was 3.5 years, and the sites of the lesions were the scrotum (one patient) and the nose (three patients). Histopathologically, there was necrotized tissue around the clefts. In addition, we detected frequent apoptotic cells around the cholesterol clefts in two of the patients by using the terminal deoxynucleotidyl transferase dUTP nick-end labeling method. Serum lipid levels were slightly elevated in two of the patients. In conclusion, cholesterol crystal deposition in basal cell carcinoma was considered to relate to a long disease duration with a tumor in a region that was subject to external irritation. Histopathologically, apoptotic cells around the cholesterol clefts indicated that lipids from the tumor cell membranes were one of the causes of cholesterol crystal deposition.
\end{abstract}

\section{Keywords}

Apoptosis, Basal Cell Carcinoma, Cholesterol Cleft, Cholesterol Crystal

\section{Introduction}

Cholesterol crystal depositions or cholesterol clefts are relatively common in xanthomas or necrobiotic xantho-

"Corresponding author.

How to cite this paper: Okamura, K., Konno, T., Kawaguchi, M., Abe, Y., Yaguchi, Y., Ajima, S., Hozumi, Y. and Suzuki, T. (2015) Cholesterol Crystal Deposition in Basal Cell Carcinoma: An Investigation of 4 Cases. Journal of Cosmetics, Dermatological Sciences and Applications, 5, 176-180. http://dx.doi.org/10.4236/jcdsa.2015.53021 
granulomas and are occasionally seen in necrobiosis lipoidica [1] [2]. This is because they consist of lipid-rich foam cells or macrophages. However, there have been few papers describing cholesterol crystal depositions in other skin tumors or skin diseases, and the mechanism(s) involved are still unknown. We present four cases of basal cell carcinoma (BCC) that contains cholesterol crystal depositions.

\section{Patients}

We examined four patients with BCC containing cholesterol crystals who visited Yamagata University Hospital between 2013 and 2014. We treated 33 BCC patients (all of them had one lesion) in this period, so the frequency of cholesterol crystal depositions in BCC was about $12 \%$. Clinical data and information were obtained from the clinical records at the hospital.

\subsection{Patient 1}

A 78-year-old Japanese man presented with a 5-year history of a mass lesion on the left side of his scrotum. The mass was $25 \times 22 \mathrm{~mm}$ in size, ulcerated at the center with a prominent border (Figure 1(a), Figure 1(b)). A skin biopsy specimen taken from the tumor confirmed a diagnosis of BCC, and the patient underwent a complete excision of the tumor. Histologically, closely-aggregated needle-shaped clefts were identified in the interstitium (Figure 1(c), Figure 1(d)). The clefts were surrounded by cells expressing CD68 antigen (Figure 1(e)). In addition, the tumor was necrotized near the clefts (Figure 1(f)). The patient had no history of hyperlipidemia. Serum levels of triglyceride and total cholesterol were within normal limits.

\subsection{Summary of the Four Patients}

The clinical and histopathological features of Patient1 and the other three patients are shown in Table 1 . The median disease duration was 3.5 years. The sites of the lesions were the scrotum (one patient) and the nose (three patients). Histopathologically, there was necrotized or keratinized tissue around the cholesterol clefts in all cases. Infiltration of histiocytes around the cholesterol clefts were detected by CD68 staining in Patient 1 on-
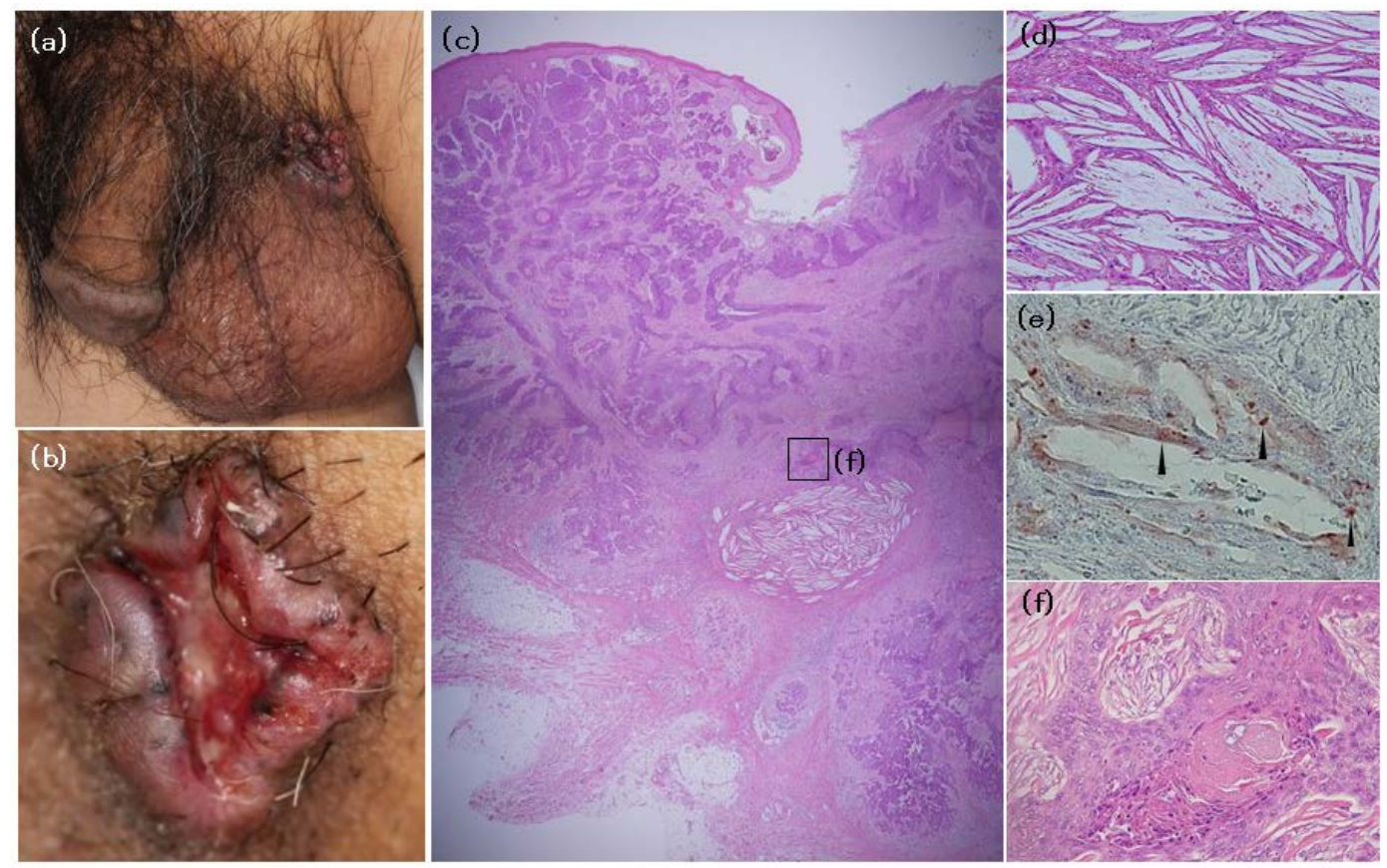

Figure 1. (a) and (b) The mass on the left side of the scrotum. It was $25 \times 22 \mathrm{~mm}$ in size, ulcerated at the center with a prominent border. (c) Nodular masses of basaloid cells, mainly in the dermis (hematoxylin-eosin [HE], original magnification $\times 40$ ); (d) Closely-aggregated needle-shaped cholesterol clefts in the interstitium of the tumor (HE, $\times 200$ ); (e) CD68 positive cells around the clefts (arrowheads, $\times 200$ ); (f) Necrotized areas near the clefts $(\mathrm{HE}, \times 200)$. 
ly. The terminal deoxynucleotidyl transferase dUTP nick-end labeling (TUNEL) method showed a high frequency of apoptotic cells around the cholesterol clefts in Patients 3 and 4 (Figure 2). Two of the patients had
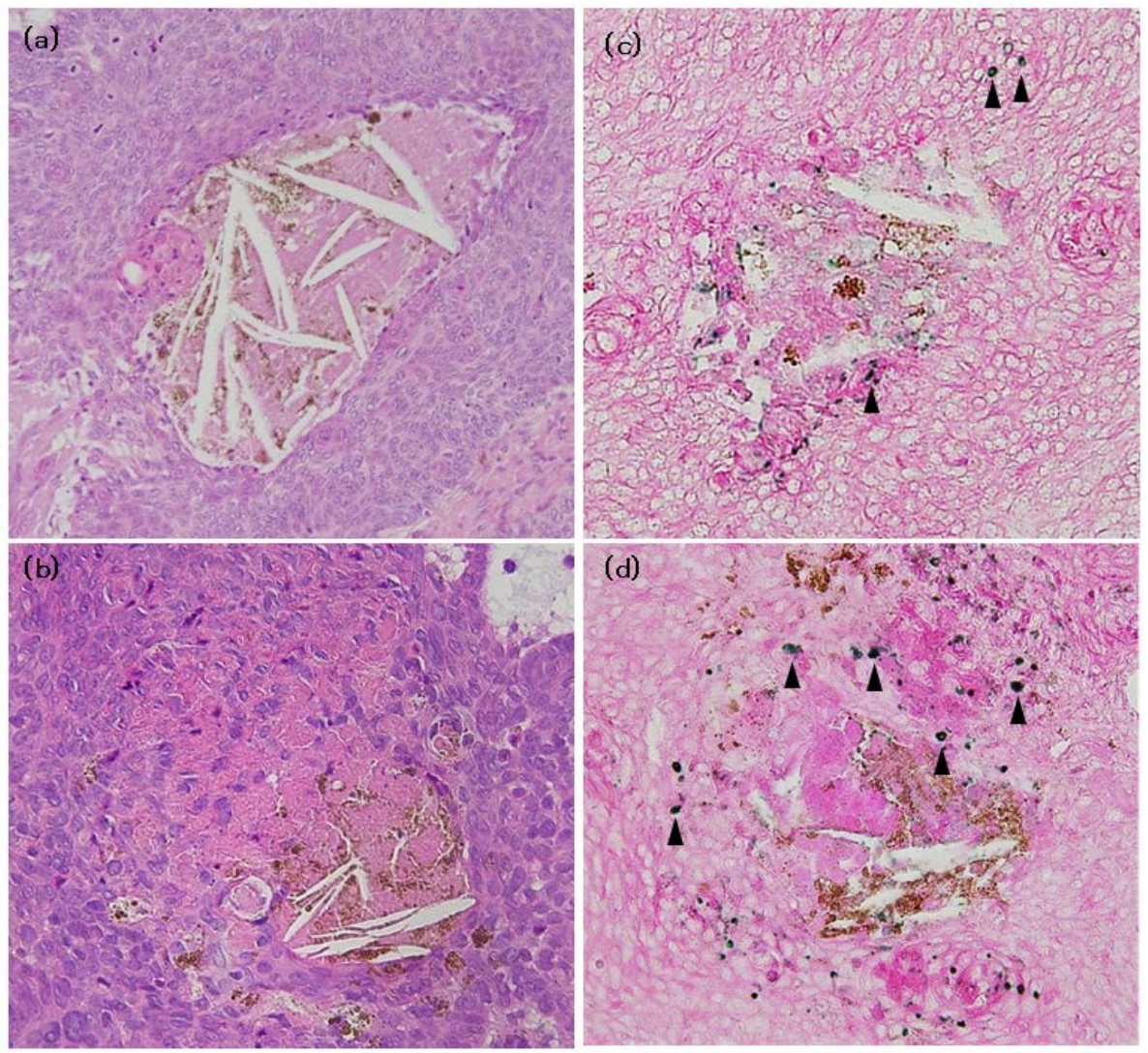

Figure 2. (a) and (b) Needle-shaped cholesterol clefts in necrotized tissue in Patients 3 and 4, respectively (HE, original magnification $\times 200$ ). (c) and (d) Apoptotic cells (stained green, arrowheads) around the cholesterol clefts in both patients (terminal deoxynucleotidyl transferase dUTP nick-end labeling method, $\times 200$ ).

Table 1. Clinical and histopathological findings of BCC patients with cholesterol crystal deposition.

\begin{tabular}{|c|c|c|c|c|}
\hline Patient No. & 1 & 2 & 3 & 4 \\
\hline Age & 78 & 79 & 83 & 76 \\
\hline Sex & M & M & $\mathrm{F}$ & M \\
\hline Disease duration (year) & 5 & 2 & 2 & 10 \\
\hline Involved site & Scrotum & Nose & Nose & Nose \\
\hline Size $(\mathrm{mm})$ & $25 \times 22$ & $5 \times 4$ & $22 \times 18$ & $7 \times 6$ \\
\hline Infiltration of histiocytes around the clefts & Positive & Negative & Negative & Negative \\
\hline apoptosis around the clefts & Negative & Negative & Positive & Positive \\
\hline Serum triglyceride $(\mathrm{mg} / \mathrm{dl})^{\mathrm{a}}$ & 56 & 105 & 205 & 120 \\
\hline Serum total choleterol $(\mathrm{mg} / \mathrm{dl})^{\mathrm{b}}$ & 158 & 230 & 256 & 216 \\
\hline Treatment & Complete excision & Complete excision & Complete excision & Complete excision \\
\hline Outcome & No recurrence & No recurrence & No recurrence & No recurrence \\
\hline
\end{tabular}

\footnotetext{
a . Normal: $<149 \mathrm{mg} / \mathrm{dl},{ }^{\text {b }}$. Normal: $<219 \mathrm{mg} / \mathrm{dl}$.
} 
mild hyperlipidemia. None of the patients had a history of familial hyperlipidemia. We could not examine the clefts with a polarization microscope, because we had not preserved the frozen specimens in all the patients.

\section{Discussion}

These four cases had three features in common: a relatively long disease duration; a tumor in a region subject to external irritation; and necrotized or keratinized tissue around the cholesterol clefts. These three features, especially the histological features, may have affected the formation of cholesterol crystals. The reasons for cholesterol crystal deposition in cutaneous or subcutaneous tissue are unclear. However, Fam speculated that repeated microtrauma to the skin can result in the release of cholesterol from erythrocyte and other cell membrane lipids, leading to cholesterol crystal formation [3]. The high frequency of apoptotic cells around the cholesterol clefts (Figure 2(c), Figure 2(d)) suggests that the release of cholesterol from tumor cell membranes caused by tumor cell apoptosis or necrosis might be one of the causes of cholesterol crystal deposition. In Patient 1, infiltration of histiocytes was detected around the cholesterol clefts (Figure 1(e)) but apoptotic cells were not. That might indicate that the clefts were not fresh lesions.

Parke et al. proposed that cholesteatomas of the orbit should be divided into two groups: "cholesterol granulomas" and "epidermoid or true cholesteatomas" [4]. The first includes lesions that contain no epithelial elements, and the second includes lesions that contain epithelial elements. We suggest a similar categorization for cholesterol crystal depositions in cutaneous and subcutaneous tissue; i.e., those without a precursor lesion, and those with a precursor lesion. The former is often accompanied by a granuloma around the cholesterol crystal, which has been reported as a "granuloma cholesterinicum subcutaneum" [5], or a "tophus-like cholesterol nodule" [6]. In addition, cholesterol crystals are occasionally detected in chronic rheumatoid arthritis, osteoarthritis, or bursal effusions [7] [8]. The cholesterol crystal depositions with a precursor lesion have been rarely reported except in tumors that contain lipid-rich cells, such as xanthomas or necrobiotic xanthogranulomas. Gibson et al. reported three cases of necrobiosis lipoidica with cholesterol clefts on the background of severe diabetes mellitus [2]. Hunt et al. reported a woman with a fibrous histiocytoma that showed cholesterol deposition in the setting of type IIB hyperlipidemia [9]. Histopathologically, these disorders show lipid-rich foam cells or macrophages on the background of hyperlipidemia or diabetes mellitus. This might be a direct cause of cholesterol crystal formation. In our cases, lipid-rich cells were not recognized around the clefts, and although two patients had a mild hyperlipidemia, we cannot demonstrate whether this was related to the formation of cholesterol crystal because of the small number of cases. Therefore, other mechanisms are considered, as described above.

In Japanese patients we sometimes observe cholesterol crystal depositions in cutaneous tumors, such as epidermal cysts, trichilemmal cysts, or pilomatricomas [10]-[12]. However, there have been few reports worldwide. This may be because cholesterol crystal depositions in cutaneous tumors do not affect the therapeutic strategy or prognosis in most cases. Further discussion of this area is expected in the future.

\section{Conclusion}

In conclusion, the present study suggests that a long disease duration with a tumor in a region that is subject to external irritation may contributes to the cholesterol crystal deposition in patients with BCC. Histopathologically, lipids from the tumor cell membranes caused by apoptosis are also considered to be one of the causes of this condition.

\section{Disclosure}

This study was an independent study and not funded by any drug companies.

\section{References}

[1] Burgdorf, W.H. and Zelger, B. (2008) The Histiocytoses. In: Elder, D.E., Ed., Lever's Histopathology of the Skin, 10th Edition, Lippincott Williams \&Wilkins, Philadelphia, 667-688.

[2] Gibson, L.E., Reizner, G.T. and Winkelmann, R.K. (1988) Necrobiosis Lipoidica Diabeticorum with Cholesterol Clefts in the Differential Diagnosis of Necrobiotic Xanthogranuloma. Journal of Cutaneous Pathology, 15, 18-21. http://dx.doi.org/10.1111/j.1600-0560.1988.tb00509.x

[3] Fam, A.G. (1989) Subcutaneous Cholesterol Crystal Deposition and Tophus Formation. Arthritis \& Rheumatology, 32, 
1190-1191. http://dx.doi.org/10.1002/anr.1780320926

[4] Parke 2nd, D.W., Font, R.L., Boniuk, M. and McCrary 3rd., J.A. (1982) "Cholesteatoma” of the Orbit. Archives of Ophthalmology, 100, 612-616. http://dx.doi.org/10.1001/archopht.1982.01030030614015

[5] Urbach, E. and Gouley, B.A. (1942) A New Form of Localized Lipoidosis: Granuloma Cholesterinicum Subcutaneum. Journal of Investigative Dermatology, 5, 331-346. http://dx.doi.org/10.1038/jid.1942.48

[6] Lanting, P.J., van Baarlen, J., Festen, J.J. and van de Laar, M.A. (1995) Tophus-Like Cholesterol Nodules in Two Patients with Rheumatoid Disease. The Journal of Rheumatology, 22, 338-341.

[7] Ettlinger, R.E. and Hunder, G.G. (1979) Synovial Effusions Containing Cholesterol Crystals; Report of 12 Patients and Review. Mayo Clinic Proceedings, 54, 366-374.

[8] Rull, M. (1997) Calcium Crystal-Associated Diseases and Miscellaneous Crystals. Current Opinion in Rheumatology, 9, 274-279. http://dx.doi.org/10.1097/00002281-199705000-00017

[9] Hunt, S.J., Santa Cruz, D.J. and Miller, C.W. (1990) Cholesterotic Fibrous Histiocytoma. Its Association with Hyperlipoproteinemia. Archives of Dermatology, 126, 506-508. http://dx.doi.org/10.1001/archderm.1990.01670280090016

[10] Ishikawa, Y., Baba, S. and Suzuki, H. (1996) Lipid-Rich Keratin Spherules Containing Cholesterol Crystals in an Epidermal Cyst. Medical Electron Microscopy, 29, 7-12. http://dx.doi.org/10.1007/BF02348071

[11] Hamada, J., Hoshino, T., Sakata, H. and Yoshida, H. (1988) Studies of Cholesterol Crystal in Epidermoid Cyst of the Hand (Original Title in Japanese). The Journal of Japanese Society for Surgery of the Hand, 5, 541-544.

[12] Matsui, K., Sakihama, H., Nakama, T.Toyama, K., Ito, E., Nohara, Y., Oshiro, C., Toyoda, Z. and Uesato, H. (1985) Clinicopathological Study of Pilomatricoma (Calcifying Epithelioma) in Okinawa (Original Title in Japanese). $P a-$ thology and Clinical, 3, 197-203. 